\title{
Understanding Patient Personality in Medical Care: Five-Factor Model
}

\author{
Donald A. Redelmeier, MD FRCPC MS(HSR) FACP ${ }^{1,2,3,4,5}$ (D), \\ Umberin Najeeb, MD FCPS(Pak) FRCPC ${ }^{1,4,5}$, and Edward E. Etchells, MD FRCPC MSc $1,4,5$
}

'Department of Medicine, University of Toronto, Toronto, Canada; ${ }^{2}$ Evaluative Clinical Sciences, Sunnybrook Research Institute, Toronto, Canada; ${ }^{3}$ Institute for Clinical Evaluative Sciences, Toronto, Canada; ${ }^{4}$ Division of General Internal Medicine, Sunnybrook Health Sciences Centre, G-151, 2075 Bayview Ave, Toronto, Ontario, Canada; ${ }^{5}$ Center for Quality Improvement \& Patient Safety, University of Toronto, Toronto, Canada.

Personality is the description of an individual's tendencies when acting or reacting to others. Clinicians spontaneously form impressions of a patient's apparent personality yet such unstructured impressions might lead to snap judgments or unhelpful labels. Here we review the evidence-based five-factor model from psychology science for understanding personalities (OCEAN taxonomy). Openness to experience is defined as the general appreciation for a variety of experiences. Conscientiousness is the tendency to exhibit self-discipline. Extraversion is the degree of engagement with the external world. Agreeableness is the general concern for social harmony. Neuroticism is the tendency to experience negative emotions. An awareness of these five dimensions might help clinicians avoid faulty judgments from casual contact. Expert assessment of personality requires extensive training and data, thereby suggesting that clinicians should take a humble view of their own unsophisticated impressions of a patient's personality.

J Gen Intern Med 36(7):2111-4

DOI: $10.1007 / \mathrm{s} 11606-021-06598-8$

(c) Society of General Internal Medicine 2021

\section{INTRODUCTION}

Delivering person-centered care means respecting that patients have personalities. These personalities influence commitment to preventive care, adherence with medications, willingness to undergo surgery, reliability with follow-up, and clinical outcomes. ${ }^{1,2}$ Adapting to different personalities is a core skill for a practicing clinician. ${ }^{3}$ General medical literature, however, is relatively silent about the normal range of personality aside from antiquated claims such as the patient's personality being linked to migraines or ulcers. ${ }^{4}$ In turn, an unstructured approach to assessing personality may result in unhelpful onedimensional labels (e.g., "pleasant" or "difficult") that foster biased intuitions about a patient's temperament and potentially undermine medical care. ${ }^{5}$

Personality is not a standard subject in evidence-based medicine. Personality is almost never the topic of a

Received September 9, 2020

Accepted January 1, 2021

Published online January 27, 2021 randomized controlled trial because it is a stable patient characteristic that cannot be readily modified by a clinician or observed to change in a study. Baseline data on personality are often unavailable for observational research grounded in chart review, clinical registries, or database analysis. The scattered comments about personality that sometime appear in medical records and are potentially available for text mining, furthermore, often say more about the author than the subject. ${ }^{6,7}$ As a consequence, patient self-report questionnaires and observational surveys tend to provide the most common evidence on personality in health care (Table 1).

Psychology science outside of medicine includes a specific branch that explores the domain of personality. The branch has many contradictory theories and findings that fail to replicate; however, one paradigm that has proven reliable is a five-factor model. ${ }^{13-15}$ The specific factors are openness, conscientiousness, extraversion, agreeableness, and neuroticism (OCEAN mnemonic). ${ }^{16-18}$ The core assumption of the OCEAN taxonomy is that a few features are reproducible traits partially predicting a person's behavior over long intervals in similar situations. ${ }^{19}$ The purpose of this article is to review the OCEAN taxonomy from a medical perspective so clinicians might have a better understanding of normal personality traits (direct treatment advice is not addressed).

\section{Openness to Experience}

Openness to experience is defined as a general appreciation for varied experiences and involves traits such as curiosity and caution. A contrasting example could be characters from the movie "Toy Story" where Buzz Lightyear might be classified as higher than Woody in openness. Some descriptive terms could include wanderlust, curiosity, or open-mindedness. In medicine, openness may possibly contribute to some diseases by increasing a patient's propensity toward risky activities such as engaging in extreme sports, exposure to exotic infections, or eating toxic mushrooms. Openness can sometimes predict a patient's responsiveness to behavioral therapy for bulimia. ${ }^{8}$ Identifying this trait requires watching for signs that the patient enjoys spontaneity, holds unconventional beliefs, or sometimes behaves unpredictably. 
Table 1 Examples of Observational Research on Personality

\begin{tabular}{|c|c|c|c|c|}
\hline$\overline{\text { Personality trait }}$ & General definition & Personal statement $*$ & Medical example $^{\dagger}$ & Clinical application $^{\S}$ \\
\hline Openness & $\begin{array}{l}\text { Appreciation for variety and } \\
\text { wanderlust }\end{array}$ & $\begin{array}{l}\text { "I enjoy trying new } \\
\text { things" }\end{array}$ & $\begin{array}{l}\text { Levallius et al. Eat } \\
\text { Behav. } 2019^{8}\end{array}$ & $\begin{array}{l}\text { Cognitive behavioral therapy for } \\
\text { bulimia more effective if higher } \\
\text { openness }\end{array}$ \\
\hline Conscientiousness & $\begin{array}{l}\text { Temperament of self- } \\
\text { discipline and orderliness }\end{array}$ & $\begin{array}{l}\text { "I am always } \\
\text { prepared" }\end{array}$ & $\begin{array}{l}\text { Weston et al. Psychol } \\
\text { Health Med. } 2019^{9}\end{array}$ & $\begin{array}{l}\text { Healthy dietary habits predicted by } \\
\text { greater levels of conscientiousness }\end{array}$ \\
\hline Extraversion & $\begin{array}{l}\text { Engagement with the } \\
\text { external world and } \\
\text { assertiveness }\end{array}$ & $\begin{array}{l}\text { "I talk with many } \\
\text { people at parties" }\end{array}$ & $\begin{array}{l}\text { Divinakumar et al. Ind } \\
\text { Psychiatry. } 2019^{10}\end{array}$ & $\begin{array}{l}\text { Nurses with lower levels of burnout } \\
\text { more likely to have higher extraversion }\end{array}$ \\
\hline Agreeableness & $\begin{array}{l}\text { Concern for social harmony } \\
\text { and politeness }\end{array}$ & $\begin{array}{l}\text { "I show my } \\
\text { gratitude"" }\end{array}$ & $\begin{array}{l}\text { Goldaracena et al. } J \\
\text { Hepatol. } 2019^{11}\end{array}$ & $\begin{array}{l}\text { More liver donations from those } \\
\text { candidates higher in agreeableness }\end{array}$ \\
\hline Neuroticism & $\begin{array}{l}\text { Tendency toward negative } \\
\text { emotion and apprehension }\end{array}$ & $\begin{array}{l}\text { "I get stressed out } \\
\text { easily" }\end{array}$ & $\begin{array}{l}\text { Sharbafchi et al. J } \\
\text { Psychosom. Res. } 2019^{12}\end{array}$ & $\begin{array}{l}\text { Larger likelihood of functional } \\
\text { dyspepsia for patients higher in } \\
\text { neuroticism }\end{array}$ \\
\hline
\end{tabular}

*Representative single question from longer self-description inventory

tSpecific citation to relevant medical publication examining personality trait

${ }^{\S}$ Finding from observational study correlating personality trait to health outcome

\section{Conscientiousness}

Conscientiousness is defined as a tendency to exhibit selfdiscipline and involves traits such as perfectionism and carelessness. A contrasting example could be television cartoon characters from the show "The Simpsons" where Marg Simpson might be classified higher than Homer Simpson in apparent conscientiousness. Some descriptive terms could include orderliness, selfdiscipline, and industriousness. In medicine, conscientiousness may possibly contribute to health outcomes by directly increasing a patient's attentiveness with physiotherapy, wound care, regular exercise, or home blood pressure monitoring. Conscientiousness can sometimes predict a patient's adherence to dietary advice. ${ }^{9}$ Identifying conscientiousness requires watching for signs that the patient has impressive focus, high self-efficacy, and a degree of steadfastness.

\section{Extraversion}

Extraversion is defined by the degree of engagement with the external world and involves traits such as being outgoing or being solitary. A contrasting example could be Muppets from the show "Sesame Street" where Ernie might be classified as higher than Bert in extraversion. Some descriptive terms could include assertiveness, warmth, and social confidence. In medicine, extraversion may possibly contribute to the risk of communicable diseases by increasing a patient's exposure to hazards spread by person-to-person contact or the power of peer pressure to influence recklessness. Extraversion can sometimes predict how work relationships mitigate burnout in nurses. ${ }^{10}$ Identifying extraversion requires watching for signs that the patient likes to talk, enjoys being the center of attention, and feels comfortable interrupting to add to the conversation.

\section{Agreeableness}

Agreeableness is defined as a general concern for social harmony including traits such as friendliness and antagonism. A contrasting example could be American presidents where Ronald Reagan might be higher than Donald Trump in apparent agreeableness. Some descriptive terms could include civility, compassion, and tact. In medicine, agreeableness may possibly reduce a patient's risks of injury due to fewer interpersonal conflicts and might also increase the availability of family supports for care. Agreeableness can predict a greater willingness toward organ donation. ${ }^{11}$ Identifying this trait requires watching for signs the patient has a trusting view of human nature, expresses gracious willingness to compromise, and sometimes ascribes to harmful societal myths (e.g., drinking methanol to fight coronavirus). ${ }^{20}$

\section{Neuroticism}

Neuroticism is defined as a tendency to experience negative emotions and involves traits such as nervousness and confidence. A contrasting example could be android characters from the movie "Star Wars" where C3P0 might be classified as higher than R2D2 in apparent neuroticism. Some descriptive terms could include timidity, pessimism, and volatility. In medicine, this trait may possibly contribute to a patient's negative reaction when learning about rare drug side-effects or when reading an online medical record that shows a marginally abnormal laboratory result. Neuroticism can sometimes predict a patient's tendency to seek care for vague abdominal dyspepsia. ${ }^{12}$ Identifying this trait requires watching for signs that the patient is easily irritated, generally apprehensive, and sometimes reluctant to digest negative information. 


\section{DISCUSSION}

This article reviews the OCEAN taxonomy for understanding patient personalities in medical practice. Typically, a patient's personality cannot be changed by a physician; instead, the taxonomy provides insights for a physician toward adjusting care to fit a patient's personality. ${ }^{21,22}$ The taxonomy can also provide systematic language for clinicians to communicate nuances to colleagues, recognize traits in a clinical interaction, or build trust by self-disclosure. ${ }^{23}$ Precise recommendations on how to treat a patient who has specific traits, however, are beyond the scope of this article because a clinical encounter is an interaction between the personality of the patient, the personality of the responsible clinician, and the personality of other involved individuals. ${ }^{24}$

A large limitation of the OCEAN taxonomy is that it is a subjective sketch. Similar to the APGAR score for assessing newborns, the OCEAN taxonomy says nothing direct about diagnosis, treatment, or prognosis. ${ }^{25}$ Unlike the APGAR score, the OCEAN taxonomy is not a single integer and stays as five dimensions instead. ${ }^{26}$ Both the APGAR and OCEAN taxonomy face criticisms due to cultural differences in defining normal, personal diversity in values, inconsistencies between assessors, and the subjective nature of ratings. ${ }^{27,28}$ This means the utility of the OCEAN taxonomy is unproven in medicine despite being standard in psychology for assessing personality. For psychopathology, the DSM-V is the standard in psychiatry for testing personality disorders. ${ }^{29}, 30$

The OCEAN taxonomy has other weaknesses since no reference gold standard is available for personality assessment. The OCEAN taxonomy is based on factor analysis derived from long questionnaires and correlations with subsequent behaviors. ${ }^{31-33}$ Human personality also has endless nuances so five simple factors cannot capture all the diversity such as humility, spirituality, and culture. ${ }^{34}$ Moreover, the current science is hardly definitive, clinicians foster their own climate for communication, and direct observations can suffer from unconscious bias. ${ }^{35-37}$ The OCEAN taxonomy, therefore, provides a compact evidence-based approach to partially describe a patient's personality and a method for supporting or refuting otherwise undeserved commentary.

A final nuance of personality science is that it is the antithesis of casual impressions arising in daily practice (or inspection of internet searches). Personality assessment is a skill requiring specialized training. A simplified OCEAN inventory tool is 50 questions long, takes $10 \mathrm{~min}$ to complete, and is not part of a routine medical encounter despite wide availability. ${ }^{38}$ Even if elicited, the data would offer little power for predicting actions in new situations. ${ }^{39}$ The fallibility means clinicians need to be wary of unwarranted impressions based on brief patient contact, unstructured observations, and single indicators. For example, agreeableness can be the most blatant yet most beguiling single trait since the patient may have a different style when you are not present. ${ }^{40}$
In summary, patient personality influences medical outcomes yet intuitive judgments of patient personality may lead to biased judgments that dismiss the patient's perspective and lead to suboptimal medical care. The OCEAN taxonomy is a rigorous model for considering patient personality that offers some structure; however, judgments of personality will remain imprecise and fallible. An awareness of the OCEAN taxonomy may help clinicians appreciate relevant patient traits as well as the limitations of casual intuitive impressions. If personality seems to be a major driver of clinical decisionmaking, consultation with a psychologist or another clinician may be justified. Ideally, clinical decisions are probably bettergrounded in factors other than patient personality.

Acknowledgments: We thank the following individuals for helpful comments on specific points: Jeannie Callum, Cindy Kao, Andrew Lustig, Fizza Mazoor, Kelvin Ng, Sheharyar Raza, Lee Ross, Raffi Rush, Steven Shumak, and John Staples.

Corresponding Author: Donald A. Redelmeier, MD FRCPC MS(HSR) FACP; Division of General Internal Medicine, Sunnybrook Health Sciences Centre, G-151, 2075 Bayview Ave, Toronto, Ontario M4N 3M5, Canada (e-mail: dar@ices.on.ca).

Funding This project was supported by the Canada Research Chair in Medical Decision Sciences and the Canadian Institutes of Health Research.

\section{Compliance with Ethical Standards:}

Conflict of Interest: The authors declare that they do not have a conflict of interest.

Public Involvement: Patients or the public were not directly involved in the design, conduct, reporting, or dissemination plans of this project.

Possible Summary Tweet: Clinicians should take a humble view of their own unsophisticated impressions of a patient's personality, particularly when contrasted with expert assessment based on psychological science.

Disclaimer: The views expressed are those of the authors and do not necessarily reflect the Ontario Ministry of Health. The funding organizations had no role in the design and conduct of the study; collection, management, analysis, and interpretation of the data; and preparation, review, or approval of the manuscript.

\section{REFERENCES}

1. Schiffer AA, Denollet J, Widdershoven JW, et al. Failure to consult for symptoms of heart failure in patients with a type-D personality. Heart 2007;93:814-818.

2. Hsin-Bang $\mathbf{L}$, Wei-Hsian $\mathbf{Y}$, Wei-Kung $\mathbf{T}$, et al. Impact of type D personality on clinical outcomes in Asian patients with stable coronary artery disease. Journal of the Formosan Medical Association 2019;118: 721-729.

3. Michel W. Personality and assesment. New York: Wiley. 1968.

4. Osler W. The Principles and Practice of Medicine. New York: D Appleton \& Co. 1892.

5. Hahn SR, Kroenke K, Spitzer RL, Brody D, Williams JB, Linzer M, deGruy FV 3rd. The difficult patient: prevalence, psychopathology, and functional impairment. J Gen Intern Med. 1996;11(1):1-8.

6. Redelmeier DA, Ross LD. Practicing medicine with colleagues: pitfalls from social psychology science. J Gen Intern Med. 2019;34(4):624-626.

7. Harrison-Bernard LM, Augustus-Wallace AC, Souza-Smith FM, Tsien F, Casey GP, Gunaldo TP. Knowledge gains in a professional development workshop on diversity, equity, inclusion, and implicit bias in academia. Adv Physiol Educ. 2020;44(3):286-294. 
8. Levallius J, Clinton D, Högdahl L, Norring C. Personality as predictor of outcome in internet-based treatment of bulimic eating disorders. Eat Behav. 2020;36:101360. https://doi.org/10.1016/j.eatbeh.2019. 101360 .

9. Weston SJ, Edmonds GW, Hill PL. Personality traits predict dietary habits in middle-to-older adults. Psychol Health Med. 2019:1-9. doi: https://doi.org/10.1080/13548506.2019.1687918.

10. Divinakumar KJ, Bhat PS, Prakash J, Srivastava K. Personality traits and its correlation to burnout in female nurses. Ind Psychiatry J. 2019;28(1):24-28.

11. Goldaracena N, Jung J, Aravinthan AD, Abbey SE, Krause S, Pritlove C, Lynch J, Wright L, Selzner N, Stunguris J, Greig P, Ghanekar A, McGilvray I, Sapisochin G, Ng VL, Levy G, Cattral M, Grant D. Donor outcomes in anonymous live liver donation. J Hepatol. 2019;71(5):951-959.

12. Sharbafchi MR, Tabatabaiyan S, Haghighatdoost F, Afshar H, Keshteli AH, Feizi A, Moghtadaee K, Roohafza HR, Adibi P. Personality traits are related to functional dyspepsia in a large sample of Iranian adults. J Psychosom Res. 2019; 129: 109912.

13. Eysenck HJ. Dimensions of personality: 16, 5, or 3: Criteria for a taxanomic paradigm. Person Individ Diff 1991;12:773-90.

14. Digman JM. Personality structure: emergency of the Five-Factor model. Ann Rev Psychol 1990;41:417-40.

15. McAdams DP, Pals JL. A new Big Five: fundamental principles for an integrataive science of personality. Amer Psychol 2006;61:204-17.

16. Goldberg LR. The development of markers for the Big-Five factor structure. Psychological Assessment 1992; 4:26-42.

17. Fleeson w. Moving personality beyond the person-situation debate: the challenge and the opportunity of within-person variability. Current Directions in Psychologicla Science 2004;13(2):83- 87.

18. Mullola S, Hakulinen C, Presseau J. Ruiz de Porras DG, Jokela M, Hintsa T, Elovainio M. Personality traits and career choices among physicians in Finland: employment sector, clinical patient contact, specialty and change of specialty. BMC Med Educ 2018;18:2-12.

19. Barrick MR, Mount KK. The Big Five personality dimensions and job performance: a meta-analysis. Personnel Psychology 1991;44:1-26.

20. Karimi N, Gambrell J. Hundreds die in Iran believing methanol drinking can fight the coronavirus. The Associated Press March 27, 2020.

21. Redelmeier DA, Dickinson VM. Determining whether a patient is feeling better: pitfalls from the science of human perception. J Gen Intern Med. 2011;26(8):900-6.

22. Redelmeier DA, Dickinson VM. Judging whether a patient is actually improving: more pitfalls from the science of human perception. J Gen Intern Med. 2012;27(9): 1195-9.

23. Richards JE, Hohl SD, Whiteside U, Ludman EJ, Grossman DC Simon GE, Shortreed SM, Lee AK, Parrish R, Shea M, Caldeiro RM, Penfold RB, Williams EC. If you listen, I will talk: the experience of being asked about suicidality during routine primary care. J Gen Intern Med. 2019;34(10):2075-2082

24. Goldberg LR. The structure of phenotypic personality traits. American Psychologist. 1993;48(1):26-34.

25. McCrae RR, Allick J. [eds]. The Five-Factor Model of personality across cultures. New York: Kluwer Academic. 2002
26. John OP, Srivastava S. (1999). The Big-Five trait taxonomy: History, measurement, and theoretical perspectives. in Pervin LA, John OP [Eds]. Handbook of Personality: Theory and Research. New York: Guilford Press. 1999.

27. Soldz S, Vaillant GE. The Big Five personality traits and the life course: A 45-year longitudinal study. Journal of Research in Personality, 1999;33:208-232.

28. Schmitt DP, Allik J, McCrae RR, Benet-Martinez V, Alcalay L, Ault L, et al. The greographic distribution of Big Five personality traits: patterns and profiles of human self-description across 56t nations. Journal of Cross-Cultural Psychology 2007;38:173-212.

29. Musson DM, Sandal G, Helmreich RL. Personality characteristics and trait clusters in final stage astronaut selection. Aviation, space, and environmental medicine. 2004;75(4):342-9.

30. Widiger TA, Simonsen E, Krueger $\mathbf{R}$, Livesley WJ, Verheul $\mathbf{R}$. Personality disorder research agenda for the DSM-V. Journal of Personality Disorders 2005;19:315-38.

31. Lawley DN, Maxwell AE. Factor analysis as a statistical method. Journal of the Royal Statistical Society. Series D 1962;12(3):209-29.

32. Norman WT. Toward an adequate taxonomy of personality attributes: replicated factors structure in peer nomination personality ratings. Journal of Abnormal and Social Psychology. 1963;66(6):574-83.

33. Biesanz JC, West SG. Towards understanding assessments of the Big Five: multitrait-multimethod analyses of convergent and discriminative validity across measurement occasion and type of observer. Journal of Personality 2004;72:845-76.

34. Mount MK, Barrick MR, Scullen SM, Rounds J. Higher-order dimensions of the big five personality traits and the big six vocational interest types. Personnel psychology. 2005 Jun;58(2):447-78.

35. Merenda PF. Toward a four-factor theory of temperament and/or personality. Journal of Personality Assessment. 1987;51(3):367-74.

36. Gallois C, Ogay T, Giles H. Communication accomodation theory: a look back and a look ahead. in Gudykunst WB [ed]. Theorizing about intercultural communication. Thousand Oaks: Sage, 2005.

37. Maina IW, Belton TD, Ginzberg S, Singh A, Johnson TJ. A decade of studying implicit racial/ethnic bias in healthcare providers using the implicit association test. Soc Sci Med. 2018;199:219-229.

38. Goldberg LR. The development of markers for the Big-Five factor structure. Psychological Assessment, 1992;4,26-42. Available online at https://openpsychometrics.org/tests/IPIP-BFFM/ (accessed May 4, 2020)

39. Chaitoff A, Rothberg MB, Windover AK, Calabrese L, Misra-Hebert AD, Martinez KA. Physician Empathy is not associated with laboratory outcomes in diabetes: a cross-sectional study. J Gen Intern Med. 2019;34(1):75-81.

40. Giles H, Ogay T. Communication accommodation theory. in Whaley BB, Samter W [eds]. Explaining communication: contemporary theories and exemplars. Mahwah, NJ: Lawrence Erlbaum, 2007.

Publisher's Note: Springer Nature remains neutral with regard to jurisdictional claims in published maps and institutional affiliations. 